\title{
Mathematical modeling of hepatitis $B$ virus infection for antiviral therapy using LHAM
}

\author{
M. Aniji ${ }^{*}$ (D), N. Kavitha ${ }^{2}$ and S. Balamuralitharan ${ }^{3}$
}

\author{
"Correspondence: \\ anijimich@gmail.com \\ ${ }^{1}$ Research Scholar, University \\ College of Engineering, Rajamadam, \\ Thanjavur District, Pattukkottai \\ 614 701, Tamil Nadu, India \\ Full list of author information is \\ available at the end of the article
}

\begin{abstract}
Anti-viral therapy is comparatively very effective for patients who get affected by the hepatitis $B$ virus. It is of prime importance to understand the different relations among the viruses, immune responses and overall health of the liver. In this paper, mathematical modeling is done to analyze and understand the effect of antiviral therapy using LHAM which describes the possible relation to HBV and target liver cells. The numerical simulations and error analysis are done up to a sixth-order approximation with the help of Matlab. This paper analyzes how the number of infected cells largely gets reduced and also how the liver damage can be controlled. Therefore, the treatment is successful for HBV infected patients.
\end{abstract}

MSC: $34 \mathrm{G} 20 ; 34 \mathrm{~A} 34$

Keywords: HBV; Antiviral therapy; LHAM; CTL; Immune; Mathematical modeling

\section{Introduction}

The study on the hepatitis B virus has gained great attention among the researchers for several decades [1]. This is because of the necessity to know in detail about a life threatening virus and, moreover, to know how it spreads. This disease spreads through physical contact, blood transfusion, and gets transmitted from the affected mother to child during the pregnancy $[2,3]$. The hepatitis B virus possibly leads to acute liver diseases. It has been noticed that most of the patients get affected with chronic HBV during birth or after the birth. A solution can be offered by mathematical models by understanding the virulence of Hepatitis B. Min et al. [4] proposed HBV infection model of ordinary differential equations of the population of uninfected target cells, infected cells and the density of virus, which will be written as

$$
\left\{\begin{array}{l}
\frac{d X}{d t}=\alpha-\varphi V X-d_{T} X, \\
\frac{d Y}{d t}=\varphi V X-b Y, \\
\frac{d V}{d t}=r Y-c Z,
\end{array}\right.
$$

where $X, Y$ and $V$ represent the concentration of uninfected target cells, infected cells, and virus particles at time $t$, respectively. The parameters $\alpha, d_{T}, \varphi, b, r, c$ are positive constants, where $\alpha$ is the production constant of the hepatocyte, $d_{T}$ is the death rate of

(c) The Author(s) 2020. This article is licensed under a Creative Commons Attribution 4.0 International License, which permits use, sharing, adaptation, distribution and reproduction in any medium or format, as long as you give appropriate credit to the original author(s) and the source, provide a link to the Creative Commons licence, and indicate if changes were made. The images or other third party material in this article are included in the article's Creative Commons licence, unless indicated otherwise in a credit line to the material. If material is not included in the article's Creative Commons licence and your intended use is not permitted by statutory regulation or exceeds the permitted use, you will need to obtain permission directly from the copyright holder. To view a copy of this licence, visit http://creativecommons.org/licenses/by/4.0/. 
the hepatocyte, $\varphi$ is the rate of infectivity, $b$ is the infected hepatocyte killing rate, $r$ is the virus production, $c$ is the virus clearance rate from the system.

In this model, a strong antitherapy is given to patients who have average immune response to clear the infected cells. Zou et al. [5] assumed that this therapy would be fit for the patients, but it is understood that it would not be suitable for the virus data. Therefore, Thornle et al. [6] introduced a better model that also does not have an effective productiveness. Though the earlier introduced methods fail to possess efficacy, a new parameter $\varepsilon$ is introduced to prohibit the growth of new virus and $\varepsilon=1$ means that therapy completely prohibits virus growth [7]. So the model is written as

$$
\left\{\begin{array}{l}
\frac{d X}{d t}=\alpha-\varphi Z X-d_{T} X \\
\frac{d Y}{d t}=\varphi Z X-b Y, \\
\frac{d V}{d t}=(1-\varepsilon) r Y-c Z .
\end{array}\right.
$$

Zou et al. [8] introduced some changes in the model. Unlike HIV infected cells, infected hepatocytes have the ability to recover because the virus does not integrate. Thus, it can be eliminated. Equation (1.2) can be modified to

$$
\left\{\begin{array}{l}
\frac{d X}{d t}=\alpha-\varphi Z X-d_{T} X+b Y \\
\frac{d Y}{d t}=\varphi V X-\delta Y-b Y \\
\frac{d V}{d t}=(1-\varepsilon) r Y-c Z
\end{array}\right.
$$

Zhang et al. [9] applied this model for prohibiting the virion production and then they investigated the drug efficacy to see whether the virion production is blocked or not. The model is written as

$$
\left\{\begin{array}{l}
\frac{d X}{d t}=\alpha+r_{X} X\left(1-\frac{X+Y}{K}\right)-(1-\eta) \varphi V X-d_{T} X+b Y, \\
\frac{d Y}{d t}=r_{Y} Y\left(1-\frac{X+Y}{K}\right)+(1-\eta) \varphi V X-\delta Y-b Y, \\
\frac{d V}{d t}=(1-\varepsilon) v Y-c Z .
\end{array}\right.
$$

Mann et al. [10] included to increase target cells and infected cells, $r_{X}$ and $r_{Y}$, respectively, and the carrying capacity. This was included in [4] together with another parameter $\eta$ which explains the effectiveness of the drug in blocking infection. Analogously to $\varepsilon$, the range for $\eta$ is $[0,1]$.

In this model, we extend the work of Khalid Hattaf et al. [11] in which the immune response of CTL cells is added in the fourth compartment. It is an action occurring in a in-host model among liver cells (uninfected and infected) and the virus, and the immune response of CTL cells is obtained by the mathematical model. Here, $X$ means the target uninfected cells (uninfected hepatocytes), $Y$ means the infected cells (infected hepatocytes), $V$ means the HBV virus and $Z$ represents the immune response of the CTL cells. This model stands for the target cells infected at the rate $\varphi$ and infection happens because of the association with target cells and virus. Initially, this target cell produces the hepatocytes at the rate $\alpha$ and the natural death rate is $d_{T}$. The infected cells die at a rate of $\delta$ and they are returned to uninfected hepatocytes at the rate $a$ for which they get infected. These infected cells are killed by the immune response of the CTL cell at a rate of $b$ and 


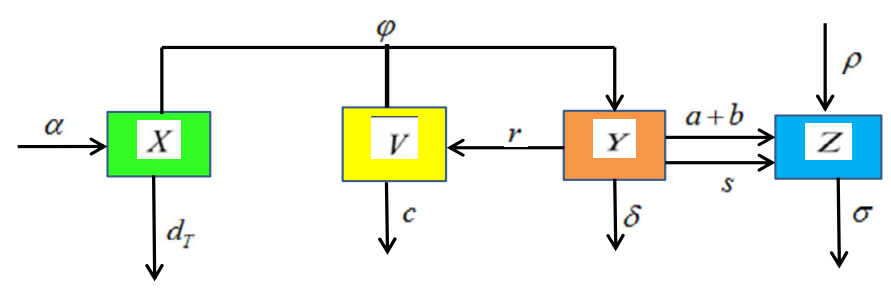

Figure 1 Compartmental diagram for HBV virus dynamics model

Table 1 The parameter values of the proposed model

\begin{tabular}{llll}
\hline Parameter & Description & Range & Unit \\
\hline$\alpha$ & Hepatocytes production rate & 1 & Cell day $^{-1} \mathrm{ml}^{-1}$ \\
$d_{T}$ & Hepatocytes death rate & $0.01-9 \times 10^{-4}$ & day $^{-1}$ \\
$\varphi$ & Infectivity rate & $1 \times 10^{-10}-6.6 \times 10^{-8}$ & $\mathrm{ml} \mathrm{virions}^{-1} \mathrm{day}^{-1}$ \\
$\delta$ & Death rate of infected hepatocytes & $0.06-0.25$ & day $^{-1}$ \\
$a$ & Return to uninfected cell rate & 0.17 & $\mathrm{Cell} \mathrm{day}^{-1} \mathrm{ml}^{-1}$ \\
$b$ & Infected cells killing rate by CTL response & $51.02-58.9$ & Cell day $^{-1} \mathrm{ml}^{-1}$ \\
$r$ & Virus production rate & $1.4-164$ & Virions cell $^{-1}$ day $^{-1}$ \\
$c$ & Decay rate & $-0.7-43.8$ & Cell day $^{-1} \mathrm{ml}^{-1}$ \\
$s$ & CTL stimulation rate & 0.4 & day $^{-1}$ \\
$\varepsilon$ & Viral load & $3 \times 10^{-4}$ & $\mathrm{ml}^{-1}$ \\
$\sigma$ & Rate of antigenic stimulation in decay absence & $1.7 \times 10^{8}$ & cells day $^{-1}$ \\
$\rho$ & export of precursor CTL cells & 427.1 & cells \\
\hline
\end{tabular}

production of new virus at a rate of $r$. The rate of decay is $c$, CTL cells can expand the immune response to viral antigen which is derived from $Y$ at a rate $s Y Z /(\varepsilon+Y)$, here the CTL stimulation rate is $s$ and the viral load is $\varepsilon$. The rate of antigenic stimulation without decay is $\sigma$. The export rate of precursor CTL cells from the thymus is $\rho$. The immune response of CTL cells has the potentiality to kill the infected cells. These assumptions lead to the model shown in Fig. 1.

We have taken four cells: uninfected target cells, the infected cells, hepatitis B virus and the CTL cells [12]. This model expresses the relation to the target liver cells and the HBV [13]. Due to the strong immune response, the HBV infection is completely cured. The compartmental diagram for HBV virus dynamics model is shown in Fig. 1 and the entire value of parameters are shown in Table 1. When our model is compared to the Min, $\mathrm{Su}$, and Kuang [4] model, the rate of recovery is not given in the target uninfected cells compartment and they did not discuss the effect of therapy in blocking infection and the effect of a drug in blocking new virus production. Similarly, Zhang, Wang, and Zhang, and Zou, Zhang, and Ruan [7, 8] did not discuss the effect of therapy in blocking infection in the compartmental target uninfected cells and infected cells. However, we elaborately discussed in our model whatever they did not discuss in their models. Already we have analyzed the nonlinear problem which matches with Mojtaba Hajipour et al's work $[14,15]$ who studied the accurate discretization of highly nonlinear boundary value problems. This work proposes a sixth-order approximation [16]; however, our work not only proposes a sixth-order approximation but also possibly a higher-order approximation for the same problem. Baleanu. et al. [17, 18] discussed a new mathematical model for HIV and the human liver using a homotopy analysis method. One also used in this work the Caputo-Fabrizio function applied to a higher-order differential equation under different conditions [19-22]. We have to use the parametric estimation for the numerical simula- 
tion [23]. This model becomes

$$
\begin{aligned}
& \frac{d X}{d t}=\alpha-d_{T} X-\varphi V X+b Y Z, \\
& \frac{d Y}{d t}=\varphi V X-\delta Y-(a+b) Y Z, \\
& \frac{d V}{d t}=r Y-c V, \\
& \frac{d Z}{d t}=\rho+\frac{s Y Z}{\varepsilon+Y}-\sigma Z .
\end{aligned}
$$

The initial and boundary conditions of finding the solution of Eq. (1.5) are

$$
\begin{aligned}
& X(0)=0 ; \quad Y(0)=0 ; \quad Y(0)=0 ; \quad Z(0)=0 ; \\
& X(0)=10^{8} ; \quad Y(0)=10^{-2} ; \quad V(0)=10 ; \quad Z(0)=100 .
\end{aligned}
$$

This forms the basis of this paper. The parameters show that some patients very quickly are cured due to the immunity response when the treatment is given but it works relatively slow for other patients [24]. So, the treatment is stopped and it is observed how the virus is degenerated in patients [25]. In this paper, we tried to have the highest understanding of the transition of the viral infection by having antiviral therapy for HBV infection. Such knowledge of understanding helps to know what treatment is to be given, when to start and how long this treatment is to be continued [26-29]. The prime objective of this paper is to obtain greater knowledge and understanding on HBV antiviral therapy for young researchers in the field of science and medicine. Generally, it is quite complex to find the analytical solution for this model. But we found the analytical solution with the use of the LHAM method in this model. Our model can be very useful for finding the analytical solution and numerical simulation in the easiest way for the similar equations using MATLAB.

This article has six parts. The initial part is an introduction dealing with existing literature and proposed work. The second and third parts are for the LHAM method and applications which are used to find the solutions. The fourth part is for the numerical experiments, and an error analysis forms the fifth part of the paper. The final part of the paper is for our conclusion.

\section{Liao's Homotopy Analysis Method (LHAM)}

We consider the equation

$$
\mathrm{K}[a(t)]=0 .
$$

Then

$$
(1-p) \Re\left[\psi(t ; p)-a_{0}(t)\right]=h p \mathrm{~A}(t) \mathrm{K}[\psi(t ; p)], \quad p \in[0,1], h \neq 0 .
$$

The above zeroth-order deformation equation stems from [30-34].

Here $\Re$ is an auxiliary linear operator such that $\Re\left[x_{i}\right]=0$ for integral constants

$$
x_{i} \quad(i=1,2,3) .
$$


When $p=0$ and $p=1,(2.1)$ can be written as

$$
\begin{aligned}
& \chi(t ; 0)=a_{0}(t) . \\
& \chi(t ; 1)=a(t) .
\end{aligned}
$$

Using a Taylor series expansion of $\chi(t ; p)$ with respect to $p$ we get

$$
\chi(t, p)=a_{0}(t)+\sum_{i=0}^{\infty} a_{i}(t) p^{i}
$$

Here $a_{i}=\left.\frac{1}{i !} \frac{\partial^{i} \chi(t ; p)}{\partial p^{i}}\right|_{p=0}$.

Differentiating the equation $i$ times with respect to $p$, then setting $p=0$, and finally dividing them by $i$ !, we get the $i$ th order deformation equations,

$$
\Re\left[a_{i}(t)-\xi_{i} a_{i-1}(t)\right]=h A(t) \beta_{i}\left[\vec{a}_{i-1}(t)\right] .
$$

Here,

$$
\beta_{i}\left[\vec{a}_{i-1}(t)\right]=\left.\frac{1}{(i-1) !} \frac{\partial^{i-1} \mathbb{R}[\psi(t ; p)]}{\partial p^{n-1}}\right|_{p=0}
$$

and also

$$
\xi_{i}=\left\{\begin{array}{cc}
0 & i \leq 1 \\
1 & i>1
\end{array}\right\}
$$

\section{Applications}

The solution of Eq. (1.5) is defined by using LHAM method as follows:

$$
\begin{aligned}
& \frac{d X}{d t}-\alpha+d_{T} X+\varphi V X-b Y Z=0 \\
& \frac{d Y}{d t}-\varphi V X+\delta Y+(a+b) Y Z=0 \\
& \frac{d V}{d t}-r Y+c V=0 \\
& \frac{d Z}{d t}-\rho-\frac{s Y Z}{\varepsilon+Y}+\sigma Z=0
\end{aligned}
$$

To obtain the analytical solution, the homotopy is

$$
\begin{aligned}
& (1-p)\left(\frac{d X}{d t}-\alpha+d_{T} X\right)=h p\left(\frac{d X}{d t}-\alpha+d_{T} X+\varphi V X-b Y Z\right) \\
& (1-p)\left(\frac{d Y}{d t}+\delta Y\right)=h p\left(\frac{d Y}{d t}-\varphi V X+\delta Y+(a+b) Y Z\right), \\
& (1-p)\left(\frac{d V}{d t}-r Y+c V\right)=h p\left(\frac{d V}{d t}-r Y+c V\right) \\
& (1-p)\left(\frac{d Z}{d t}-\rho+\sigma Z\right)=h p\left(\frac{d Z}{d t}-\rho-\frac{s Y Z}{\varepsilon+Y}+\sigma Z\right) .
\end{aligned}
$$


Equating $p^{0}$ terms we get

$$
\begin{aligned}
& p^{0}:\left(\frac{d X_{0}}{d t}-\alpha+d_{T} X_{0}\right)=0, \\
& p^{0}:\left(\frac{d Y_{0}}{d t}+\delta Y_{0}\right)=0, \\
& p^{0}:\left(\frac{d V_{0}}{d t}-r Y_{0}+c V_{0}\right)=0, \\
& p^{0}:\left(\frac{d Z_{0}}{d t}-\rho+\sigma Z_{0}\right)=0 .
\end{aligned}
$$

From Eq. (3.9) $\Rightarrow X_{0}=\left(10^{8}-\frac{\alpha}{d_{T}}\right) e^{-d_{T} t}+\frac{\alpha}{d_{T}}$.

From Eq. (3.10) $\Rightarrow Y_{0}=10^{-2} e^{-\delta t}$.

From Eq. $(3.11) \Rightarrow V_{0}=\left(10-\frac{r 10^{-2}}{c}\right) e^{-c t}+\frac{r 10^{-2}}{c}$.

From Eq. (3.12) $\Rightarrow Z_{0}=\left(100-\frac{\rho}{\sigma}\right) e^{-\sigma t}+\frac{\rho}{\sigma}$.

Again equating $p^{1}$ terms we get

$$
\begin{aligned}
& p^{1}: \frac{d X_{1}}{d t}+d_{T} X_{1}-\frac{d X_{0}}{d t}-d_{T} X_{0}=h\left(\frac{d X_{0}}{d t}-\alpha+d_{T} X_{0}+\varphi V_{0} X_{0}-(a+b) Y_{0} Z_{0}\right), \\
& p^{1}: \frac{d Y_{1}}{d t}+\delta Y_{1}-\frac{d Y_{0}}{d t}-\delta Y_{0}=h\left(\frac{d Y_{0}}{d t}-\varphi V_{0} X_{0}+\delta Y_{0}+(a+b) Y_{0} Z_{0}\right), \\
& p^{1}: \frac{d V_{1}}{d t}-r Y_{1}+c V_{1}-\frac{d V_{0}}{d t}+r Y_{0}-c V_{0}=h\left(\frac{d V_{0}}{d t}-r Y+c V_{0}\right), \\
& p^{1}: \frac{d Z_{1}}{d t}+\sigma Z_{1}-\frac{d Z_{0}}{d t}-\sigma Z_{0}=h\left(\frac{d Z_{0}}{d t}-\rho-\frac{s Y_{0} Z_{0}}{\varepsilon+Y_{0}}+\sigma Z_{0}\right) .
\end{aligned}
$$

From Eq. (3.13) $\Rightarrow X_{1}=\left(10^{8}-\frac{\lambda_{1}}{\delta+\sigma-d_{T}}-\frac{\lambda_{2}}{\delta-d_{T}}-\frac{\lambda_{3}}{c+d_{T}}-\frac{\lambda_{4}}{d_{T}}\right) e^{-d_{T} t}+\frac{\lambda_{1} e^{-(\delta+\sigma) t}}{\delta+\sigma-d_{T}}+\frac{\lambda_{2} e^{-\delta t}}{\delta-d_{T}}+\frac{\lambda_{3} e^{-c t}}{c+d_{T}}+\frac{\lambda_{4}}{d_{T}}$. Here

$$
\begin{aligned}
& \lambda_{1}=b 10^{-2}\left(100-\frac{\rho}{\sigma}\right) ; \quad \lambda_{2}=\frac{b \rho}{\sigma} ; \quad \lambda_{3}=h \varphi\left(10-\frac{r 10^{-2}}{c}\right)+\frac{h r 10^{-2}}{c} ; \\
& \lambda_{4}=\frac{\alpha}{d_{T}}(1+h)-h \alpha .
\end{aligned}
$$

From Eq. (3.14) $\Rightarrow Y_{1}=\left(10^{-2}+\frac{\lambda_{6}}{c-\delta+d_{T}}+\frac{\lambda_{7}}{d_{T}-\delta}+\frac{\lambda_{8}}{c}+\frac{\lambda_{9}}{\delta}\right) e^{-\delta t}+t \lambda_{5} e^{-\delta t}-\frac{\lambda_{6} e^{-\left(c+d_{T}\right) t}}{c-\delta+d_{T}}-\frac{\lambda_{7} e^{-d_{T} t}}{d_{T}-\delta}-$ $\frac{\lambda_{8} e^{-(\delta+c) t}}{c}+\frac{\lambda_{9}}{\delta}$. Here

$$
\begin{aligned}
& \lambda_{5}=\frac{h \rho(a+b)}{\sigma} ; \quad \lambda_{6}=h \varphi\left(10-\frac{r 10^{-2}}{c}\right)\left(10^{8}-\frac{\alpha}{d_{T}}\right) ; \\
& \lambda_{7}=\left(\frac{h \varphi r 10^{-2}}{c}\right)\left(10^{8}-\frac{\alpha}{d_{T}}\right) ; \quad \lambda_{8}=10^{-2} h(a+b)\left(100-\frac{\rho}{\sigma}\right) ; \\
& \lambda_{9}=\frac{10^{-2} h \varphi r \alpha}{c d_{T}} .
\end{aligned}
$$


From Eq. (3.15) $\Rightarrow V_{1}=\left[10-\frac{\psi_{1}}{c-\delta}+\frac{\psi_{3}}{d_{T}}+\frac{\psi_{4}}{c-d_{T}}+\frac{\psi_{5}}{\delta}+\frac{\psi_{6}}{c}\right] e^{-c t}+\frac{e^{-\delta t}}{c-\delta}\left(\psi_{1}-t \psi_{2}\right)+\frac{\psi_{3} e^{-\left(c+d_{T}\right) t}}{d_{T}}+$ $\frac{\psi_{4} e^{-d_{T} t}}{c-d_{T}}+\frac{\psi_{5} e^{-(\delta+c) t}}{\delta}+\frac{\psi_{6}}{c}$, where

$$
\begin{aligned}
& \psi_{1}=r\left[\frac{\lambda_{6}}{c+d_{T}-\delta}+\frac{\lambda_{7}}{d_{T}-\delta}+\frac{\lambda_{8}}{c}-\frac{\lambda_{9}}{\delta}-10^{-2} h\right] ; \quad \psi_{2}=r t \lambda_{5} ; \quad \psi_{3}=\frac{r \lambda_{6}}{c+d_{T}-\delta} \\
& \psi_{4}=\frac{r \lambda_{7}}{d_{T}-\delta} ; \quad \psi_{5}=\frac{r \lambda_{8}}{c} ; \quad \psi_{6}=r\left(10^{-2}+h+\frac{\lambda_{9}}{\delta}\right) .
\end{aligned}
$$

From Eq. (3.16) $\Rightarrow Z_{1}=\left(100-\frac{\xi_{1}}{\delta-\sigma}+\frac{\xi_{2}}{\delta}\right) e^{-\sigma t}+2 t(-100 \sigma+\rho) e^{-\sigma t}+\frac{\xi_{1} e^{-\delta t}}{\delta-\sigma}-\frac{\xi_{2} e^{-(\delta+\sigma) t}}{\delta}$.

Here

$$
\xi_{1}=\frac{h \sigma s}{\varepsilon+10^{-2}} ; \quad \xi_{2}=\frac{10^{-2} h s \rho}{\varepsilon+10^{-2}}
$$

The analytical solution of this model using the LHAM is

$$
X(t)=\lambda e^{-d_{T} t}+\frac{\lambda_{1} e^{-(\delta+\sigma) t}}{\delta+\sigma-d_{T}}+\frac{\lambda_{2} e^{-\delta t}}{\delta-d_{T}}+\frac{\lambda_{3} e^{-c t}}{c+d_{T}}+\frac{\lambda_{4}}{d_{T}} .
$$

Here $\lambda=99980099.99, \lambda_{1}=58.89999852, \lambda_{2}=0.000147978, \lambda_{3}=0.003196348, \lambda_{4}=199$.

$$
\begin{aligned}
& \therefore X(t)=99980099.99 e^{-0.01 t}+3.76 \times 10^{-7} e^{-170000000.1 t} \\
& +2.9596 \times 10^{-3} e^{-0.06 t}+7.796 \times 10^{-3} e^{0.7 t}+19900 . \\
& Y(t)=\varpi e^{-\delta t}+t \lambda_{5} e^{-\delta t}-\frac{\lambda_{6} e^{-\left(c+d_{T}\right) t}}{c-\delta+d_{T}}-\frac{\lambda_{7} e^{-d_{T} t}}{d_{T}-\delta}-\frac{\lambda_{8} e^{-(\delta+c) t}}{c}+\frac{\lambda_{9}}{\delta} .
\end{aligned}
$$

Here $\varpi=7.362624103, \lambda_{5}=1.484046882 \times 10^{12}, \lambda_{6}=2.0999979, \lambda_{7}=-2 \times 10^{-4}, \lambda_{8}=$ $59.06999852, \lambda_{9}=3.196347032 \times 10^{-12}$.

$$
\begin{aligned}
& \therefore Y(t)= 7.362624103 e^{-0.06 t}+t 1.484046882 \times 10^{12} e^{-0.06 t}-5.999994 e^{0.71 t} \\
&-4 \times 10^{-3} e^{-0.01 t}-1.348630103 e^{0.64 t}+5.327245053 \times 10^{-11}, \\
& V(t)=\varsigma e^{-c t}+\frac{\psi_{1} e^{-\delta t}}{c-\delta}-\frac{\psi_{2} t e^{-\delta t}}{c-\delta}+\frac{\psi_{3} e^{-\left(c+d_{T}\right) t}}{d_{T}}+\frac{\psi_{4} e^{-d_{T} t}}{c-d_{T}}+\frac{\psi_{5} e^{-(\delta+c) t}}{\delta}+\frac{\psi_{6}}{c} .
\end{aligned}
$$

Here $\varsigma=-861.7346244, \psi_{1}=10.27967374, \psi_{2}=2.077665635 \times 10^{12}, \psi_{3}=8.3999916$, $\psi_{4}=0.0056, \psi_{5}=1.888082144, \psi_{6}=1.414$.

$$
\begin{aligned}
& \therefore V(t)=-861.7346244 e^{0.7 t}+0.23501769 e^{-0.06 t}-4.750035745 e^{-0.06 t} \\
&+839.99916 e^{0.69 t}+1.27883 \times 10^{-4} e^{-0.01 t}+31.46803573 e^{0.64 t} \\
&+3.2283105 \times 10^{-2} \\
& Z(t)=\vartheta e^{-\sigma t}+2 t(-100 \sigma+\rho) e^{-\sigma t}+\frac{\xi_{1} e^{-\delta t}}{\delta-\sigma}-\frac{\xi_{2} e^{-(\delta+\sigma) t}}{\delta}
\end{aligned}
$$

Here $\vartheta=2903.236246, \xi_{1}=6601941748, \xi_{2}=165.8640777$

$$
\begin{aligned}
\therefore Z(t)= & 2903.236246 e^{-1.7 \times 10^{8} t}-3.399999915 \times 10^{10} t e^{-1.7 \times 10^{8} t} \\
& -38.83495148 e^{-0.06 t}-2764.401295 e^{-170000000.1 t}
\end{aligned}
$$




\section{Numerical experiment}

Let us consider the values for numerical results are

$$
X_{0}=10^{8}, \quad Y_{0}=10^{-2}, \quad V_{0}=10, \quad Z_{0}=100 .
$$

Let us use Matlab software to obtain the sixth-order expansions for $X(t), Y(t), V(t)$ and $Z(t)$ :

$$
\begin{aligned}
X(t)= & 10,00,00,000+9,99,80,234.978 h t+8,87,34,454.347 h^{2} t \\
& +47,58,843.56 h^{3} t+7,54,53,444.757 h^{4} t+4,66,76,678.34 h^{5} t \\
& +92,392.342 h^{6} t+46,347.647 h^{2} t^{2}+6,37,299.23 h^{3} t^{2}+2,326.8293 h^{4} t^{2} \\
& +789.737 h^{5} t^{2}+6.67889 h^{6} t^{2}+0.63467343 h^{3} t^{3} \\
& +2.6646 h^{4} t^{3}+10.2980376 h^{5} t^{3}+0.9864763638 h^{6} t^{3}+\cdots \\
Y(t)= & 0.01+0.03889431 h t+0.04545347 h^{2} t+0.0845956 h^{3} t \\
& +0.75743507 h^{4} t+0.043455634 h^{5} t+0.420346045 h^{6} t \\
& +0.63242347 h^{2} t^{2}+0.22478453 h^{3} t^{2}+0.18200093 h^{4} t^{2} \\
& +0.700037 h^{5} t^{2}+0.6734889 h^{6} t^{2}+0.00634343 h^{3} t^{3} \\
& +0.05464646 h^{4} t^{3}+0.1046667465 h^{5} t^{3}+0.9354378 h^{6} t^{3}+\cdots \\
V(t)= & 10+620.5464546761 h t+4.4746545 h^{2} t+30.3465436576 h^{3} t \\
& +2.7346566 h^{4} t+0.05575634 h^{5} t+1.444567045 h^{6} t+5.45656347 h^{2} t^{2} \\
& +0.22765803 h^{3} t^{2}+140.74687649 h^{4} t^{2}+45.4455657 h^{5} t^{2} \\
& +99.645465698 h^{6} t^{2}+80.00698765 h^{3} t^{3}+00.976534646 h^{4} t^{3} \\
& +6.196465465 h^{5} t^{3}+750.32126378 h^{6} t^{3}+\cdots \\
Z(t)= & 100+464.85565555 h t+46.654222 h^{2} t+355.255015 h^{3} t \\
& +587.466621336 h^{4} t+54.22233021 h^{5} t+41.555501 h^{6} t \\
& +23.517347 h^{2} t^{2}+78.15553697 h^{3} t^{2}+102.6879412 h^{4} t^{2} \\
& +478.66987132 h^{5} t^{2}+785.6694125 h^{6} t^{2}+74.68841269 h^{3} t^{3} \\
& +2.3698455 h^{4} t^{3}+40.368715 h^{5} t^{3}+72.3684156 h^{6} t^{3}+\cdots \\
& +\cdots
\end{aligned}
$$

We have plotted the target uninfected cell rate, the infected cell rate, the virus rate and the CTL cell response rate observing the values of parameters using Wolfram Mathematica 12 software. For doing the mathematical modeling, we used 12 parameters at different values that explain the differences seen in the data among patients undergoing combination therapy. When the antiviral therapy is given, the target rate of uninfected cell is completely increased [35]. In particular, if the death rate of hepatocytes gets decreased during the antiviral therapy then the target uninfected cell rate would also increase [36]. After that, the killing rate of the infected hepatocytes will be increased as we give the treatment. 
Since a prompt treatment is given, the death rate of both hepatocytes and the HBV infection decreases significantly $[7-10,35]$. When the rate of virus clearance increases through the application of the treatment, the rate of infected cell decreases. At first, we give the treatment for killing the infected hepatocytes and then the treatment is given for HBV infection. As the rate of virus clearance increases through the proper treatment, the infected cell rate gets reduced. Consequently, the virus clearance rate of infected cells decreased.

When the regular treatment is given, the death rate of hepatocytes as well as virus rate will be decreased [37]. When the treatment is continued, the production of new virus and the virus infectivity rate get massively reduced [38]. The killing rate of infected hepatocytes increases as the treatment is regularly given and the virus production is completely reduced to the percentage zero. The new virus production will be completely blocked since the treatment is continued for a period of time; therefore the virus production will be completely decreased to the level zero. Consequently, the patient becomes disease free as the liver cells get cured completely. He or she can be stable and lead a normal life. This is possible only due to the therapy; otherwise the death of the patient is inevitable.

\section{Error analysis}

For getting the convergence solution, we substitute Eqs. (4.1) to (4.4) in (1.5) which is recommended by Liao [31-34]. Figures 2-9 show the plots of third- and fourth-order approximations of $X(t), Y(t), V(t)$ and $Z(t)$. It is clear from these curves that the valid region of ' $h$ ' is parallel to the horizontal axis. The valid region of $h$ value ranges are given in Table 2. Figures 10-13 show the residual error function of Eqs. (5.1) to (5.4) using the third-order approximate solution for the different values of $h=-1.1, h=-1.2, h=-0.62$ and $h=-1.4$. Figures $14-17$ show the optimum and minimum values of $h$, the minimum values are shown in Table 3 and the residual errors are calculated in Table 4. We have

$$
\begin{aligned}
E R_{1}\left(X, Y, V, Z ; h_{1}\right)= & \frac{d \phi_{X}\left(t ; h_{1}\right)}{d t}-\alpha+d_{T X}\left(t ; h_{1}\right)+\varphi_{V}\left(t ; h_{1}\right)_{X}\left(t ; h_{1}\right) \\
& -b_{Y}\left(t ; h_{1}\right)_{Z}\left(t ; h_{1}\right),
\end{aligned}
$$

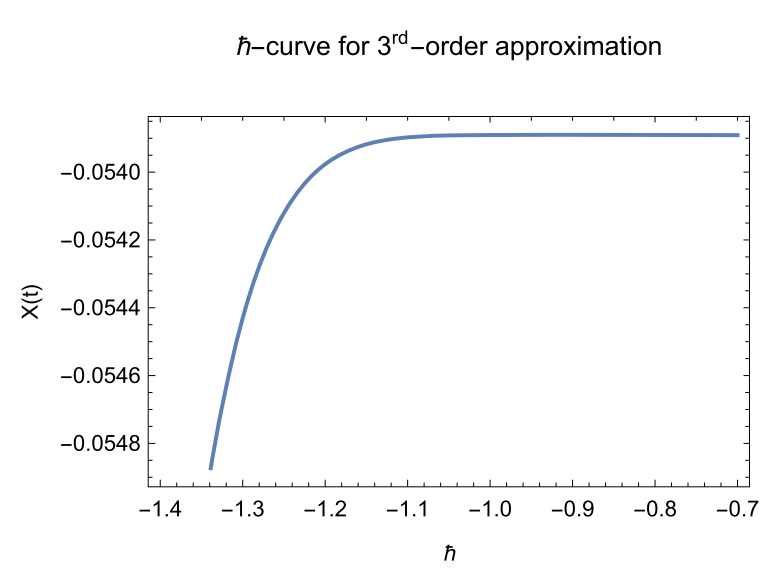

Figure 2 The $h$-curves of the third-order approximations for $X(t)$ 


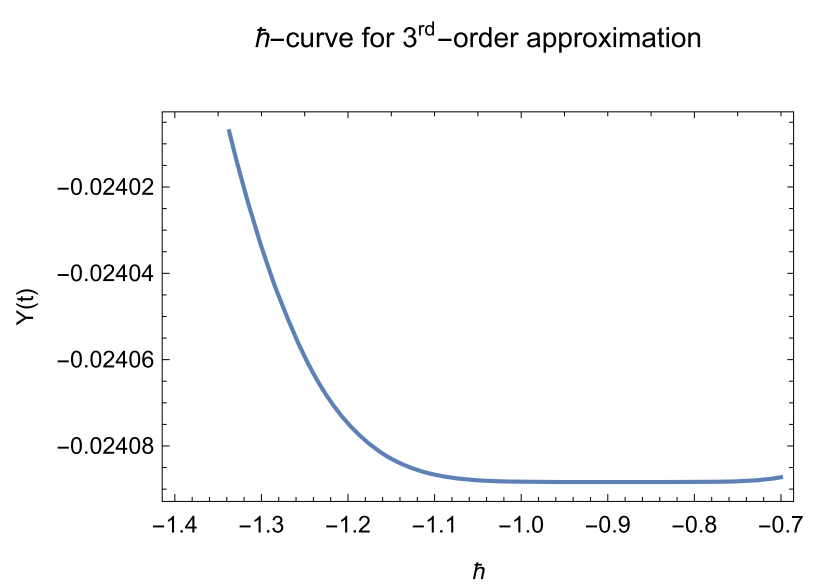

Figure 3 The $h$-curves of the third-order approximations for $Y(t)$

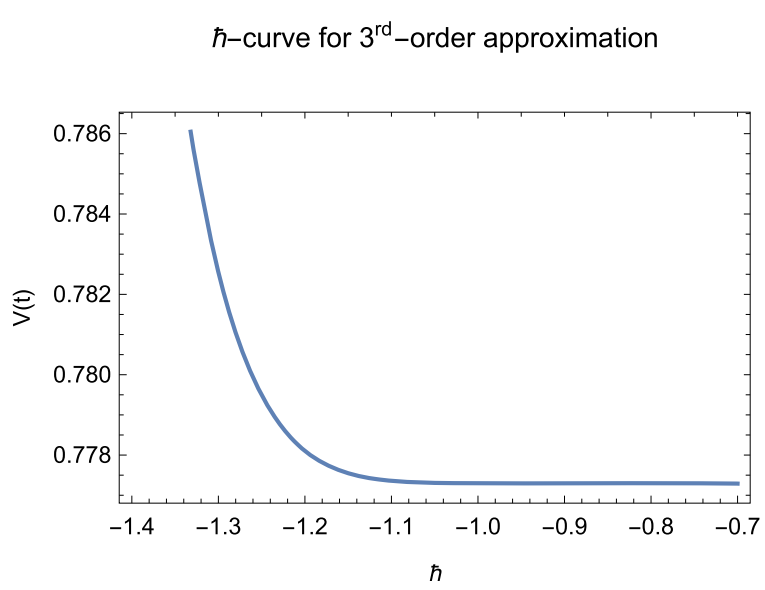

Figure 4 The $h$-curves of the third-order approximations for $V(t)$

$\hbar$-curve for $3^{\text {rd }}$-order approximation

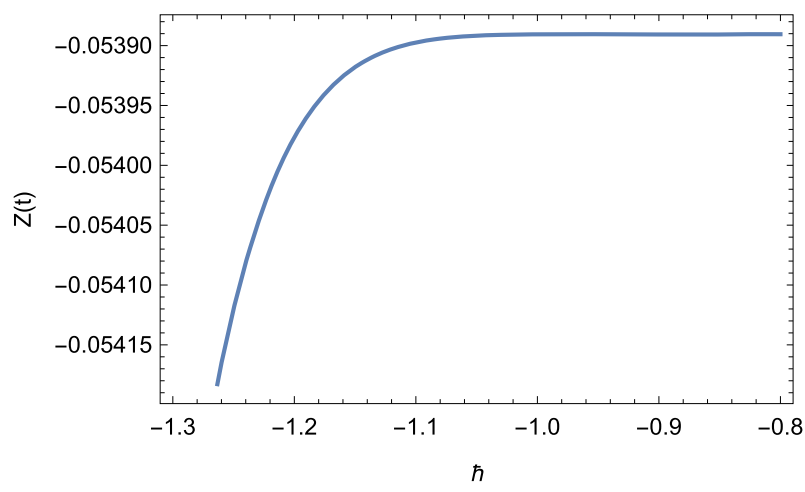

Figure 5 The $h$-curves of the third-order approximations for $Z(t)$ 


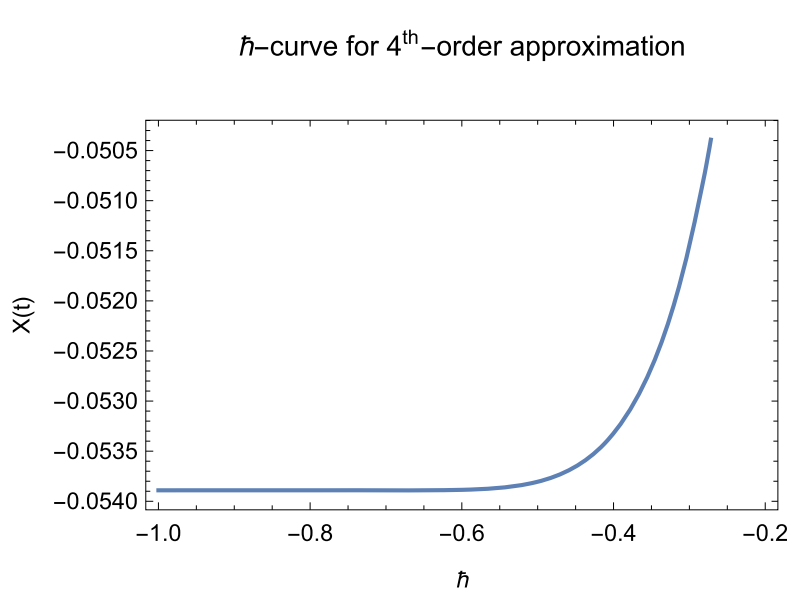

Figure 6 The $h$-curves of the fourth-order approximations for $X(t)$

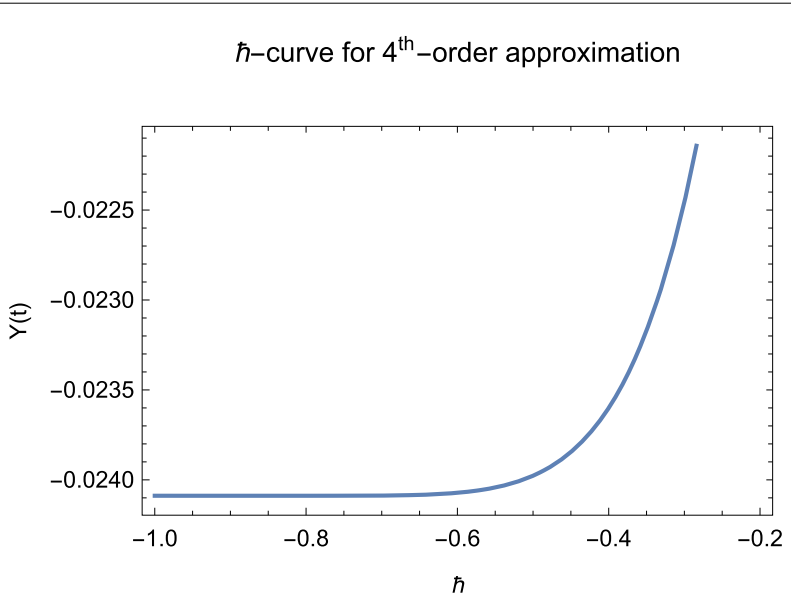

Figure 7 The $h$-curves of the fourth-order approximations for $Y(t)$

$\hbar$-curve for $4^{\text {th }}$-order approximation

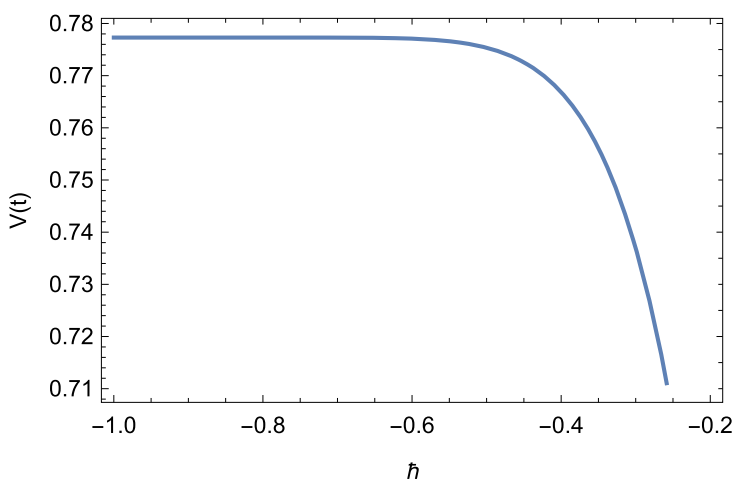

Figure 8 The $h$-curves of the fourth-order approximations for $V(t)$ 


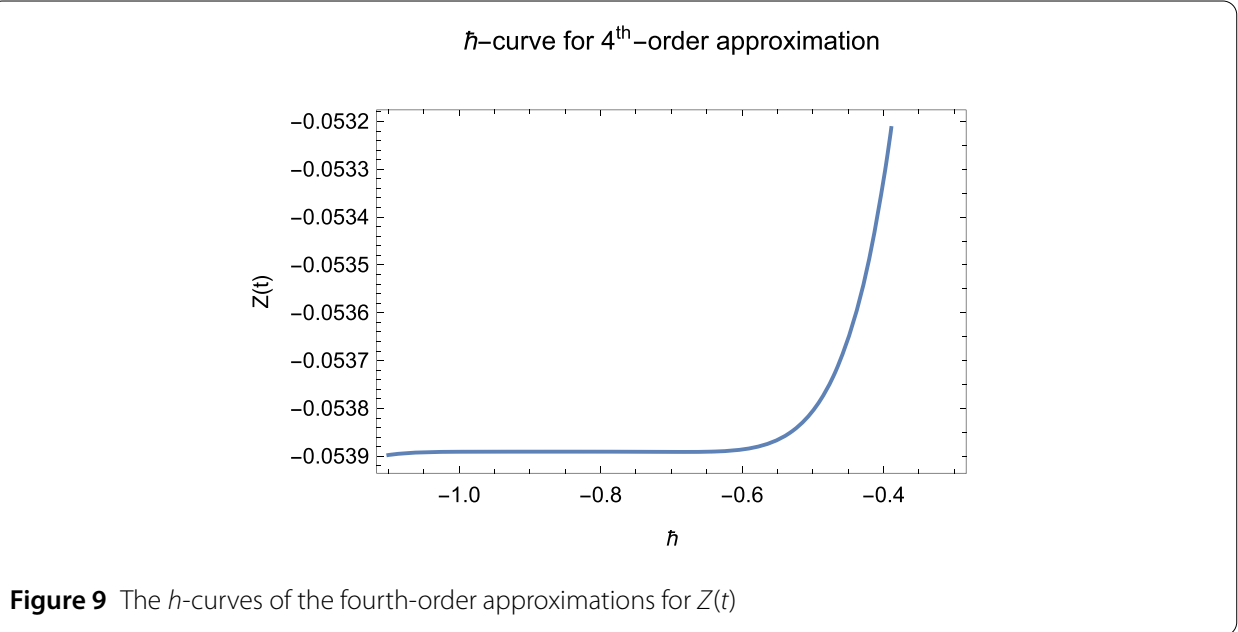

Table 2 The $h$ value is

\begin{tabular}{ll}
\hline$X(t)$ & $-1.2 \leq h \leq-0.5$ \\
$Y(t)$ & $-1.4 \leq h \leq-0.7$ \\
$V(t)$ & $-1.5 \leq h \leq-0.6$ \\
$Z(t)$ & $-1.6 \leq h \leq-0.3$ \\
\hline
\end{tabular}

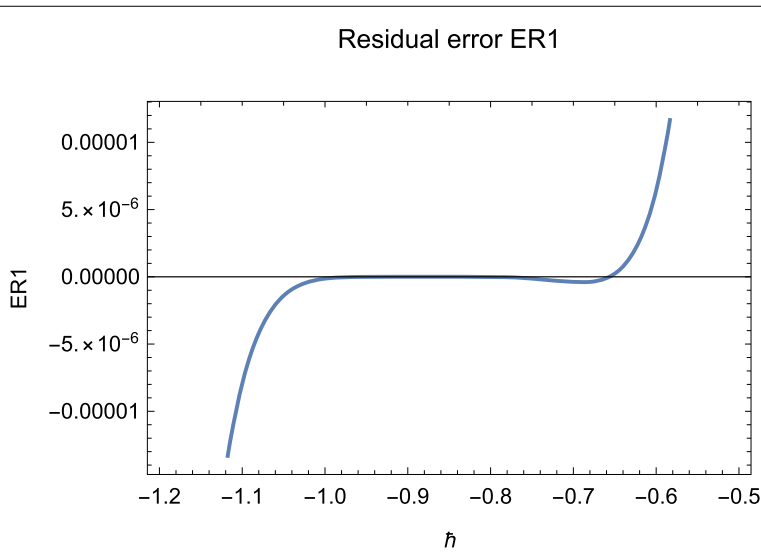

Figure 10 The residual error function of Eq. (5.1)

$$
\begin{aligned}
& E R_{2}\left(X, Y, V, Z ; h_{2}\right)=\frac{d \phi_{Y}\left(t ; h_{2}\right)}{d t}-\varphi_{V}\left(t ; h_{2}\right)_{X}\left(t ; h_{2}\right)+\delta_{Y}\left(t ; h_{2}\right) \\
& +(a+b)_{Y}\left(t ; h_{2}\right)_{Z}\left(t ; h_{2}\right) \\
& E R_{3}\left(X, Y, V, Z ; h_{3}\right)=\frac{d \phi_{V}\left(t ; h_{3}\right)}{d t}-r_{Y}\left(t ; h_{3}\right)+c_{V}\left(t ; h_{3}\right), \\
& E R_{4}\left(X, Y, V, Z ; h_{4}\right)=\frac{d \phi_{Z}\left(t ; h_{4}\right)}{d t}-\rho-\frac{s_{Y}\left(t ; h_{4}\right)_{Z}\left(t ; h_{4}\right)}{\varepsilon+_{Y}\left(t ; h_{4}\right)}+\sigma_{Z}\left(t ; h_{4}\right) .
\end{aligned}
$$

Let us consider the square residual error for sixth order approximation:

$$
R X\left(h_{1}\right)=\int_{0}^{1}\left(E R_{1}\left(X, Y, V, Z ; h_{1}\right)\right)^{2} d t
$$




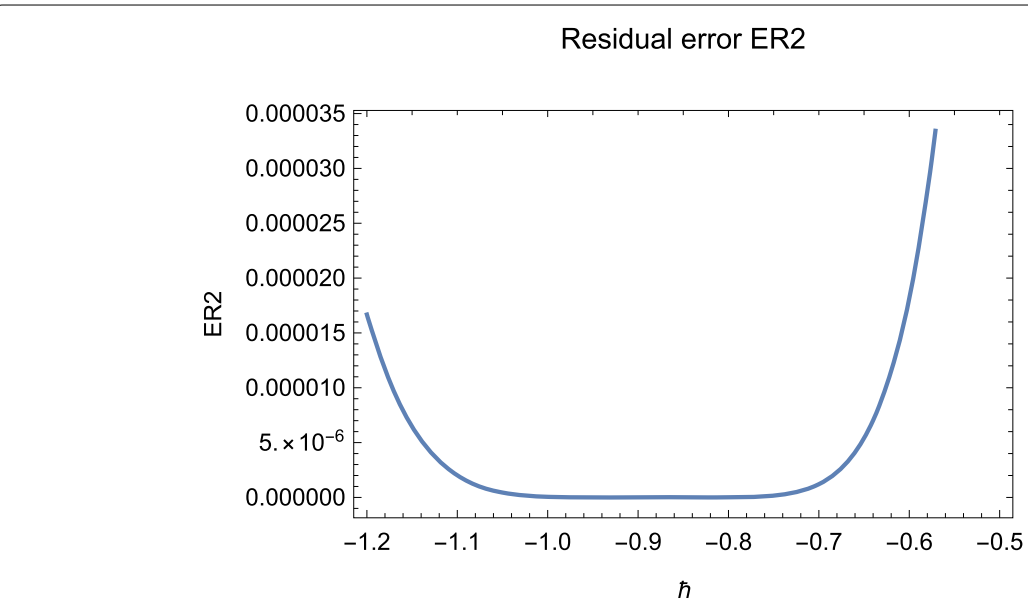

Figure 11 The residual error function of Eq. (5.2)

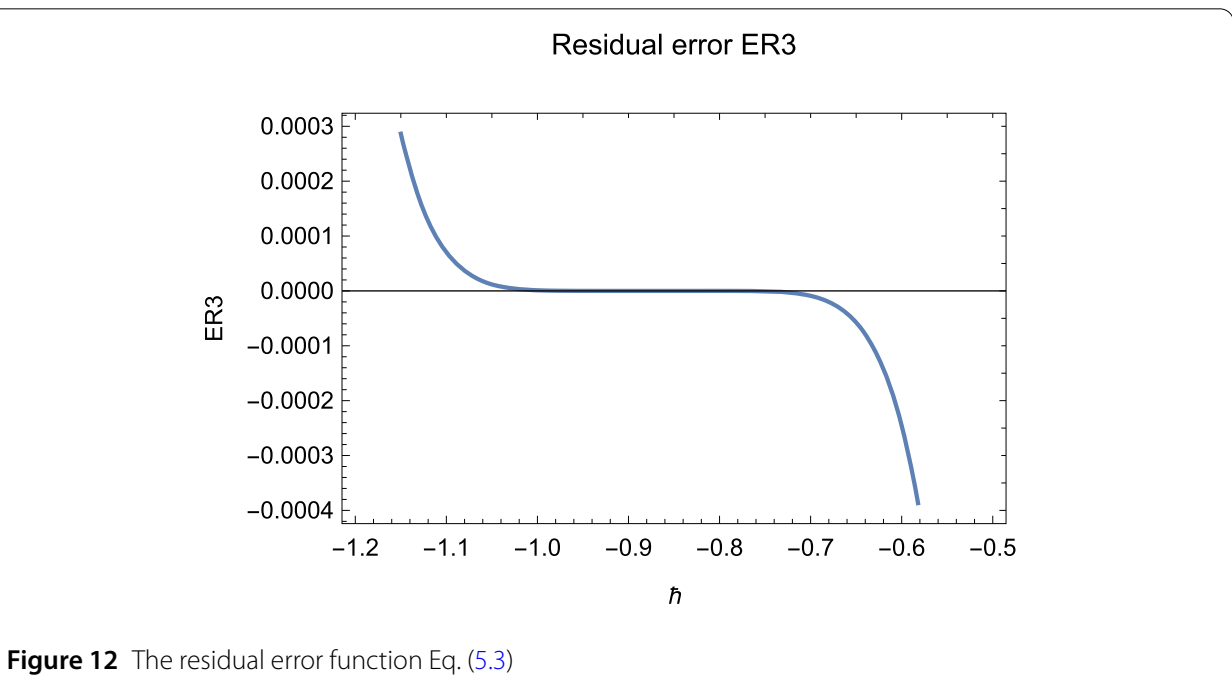

Figure 12 The residual error function Eq. (5.3)

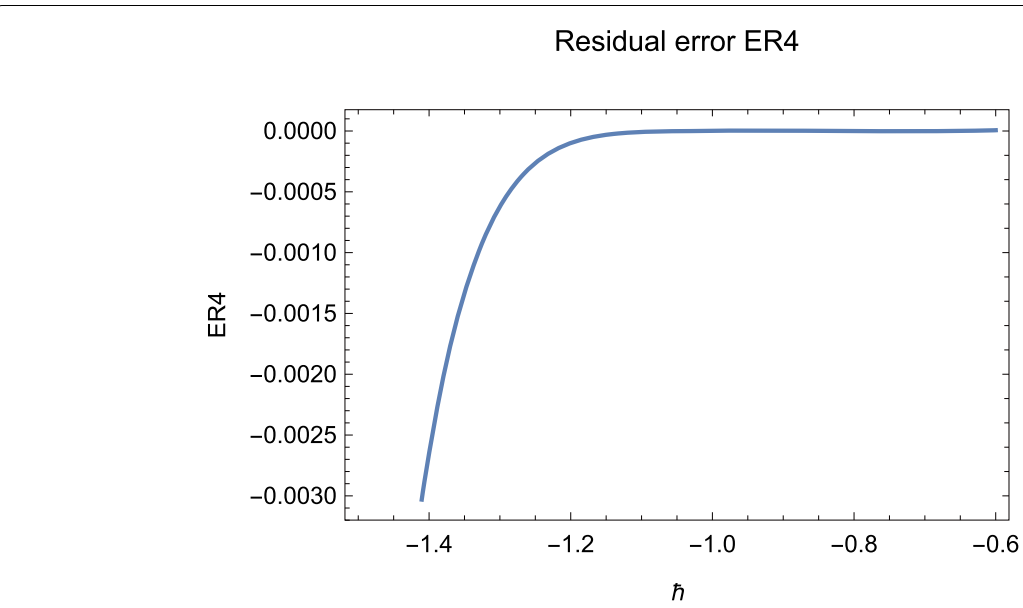

Figure 13 The residual error function Eq. (5.4) 


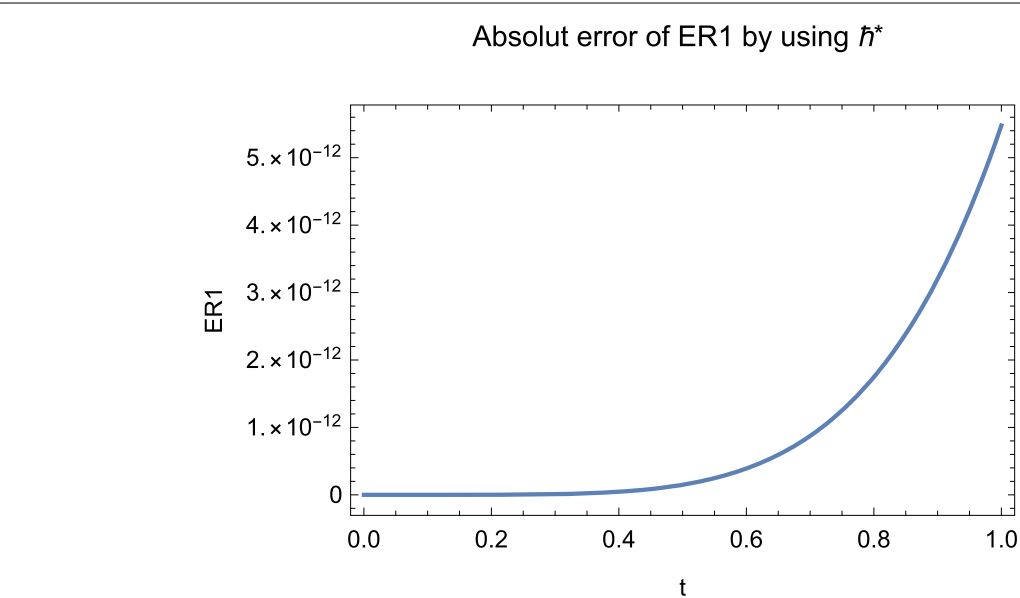

Figure 14 The optimum and minimum values of $X(t)$

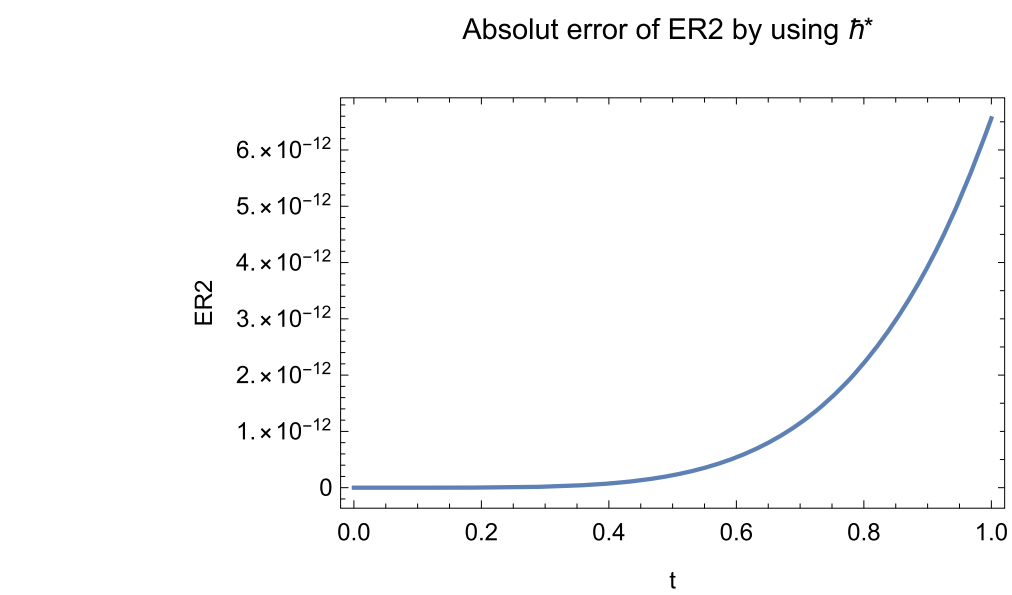

Figure 15 The optimum and minimum values of $Y(t)$

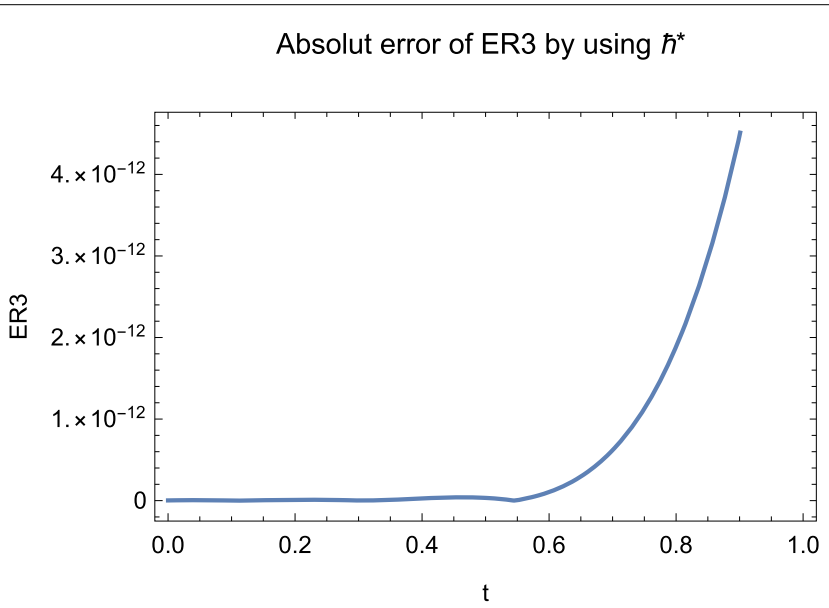

Figure 16 The optimum and minimum values of $V(t)$ 


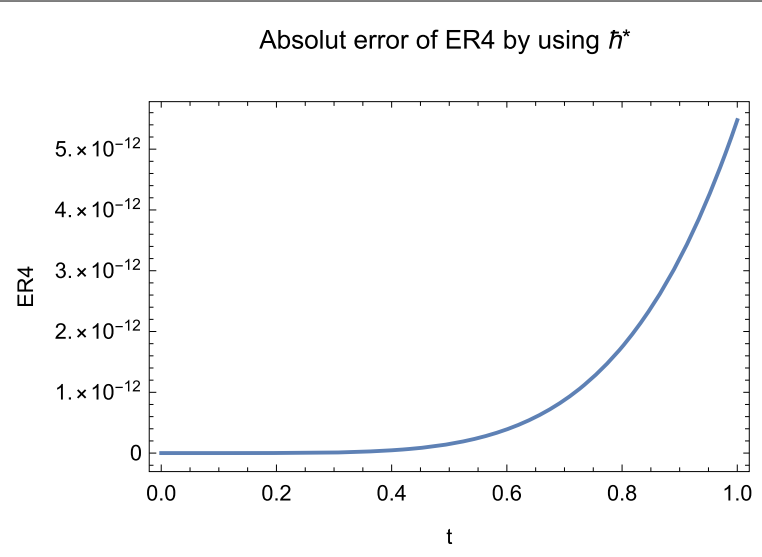

Figure 17 The optimum and minimum values of $Z(t)$

Table 3 The minimum values of $R X\left(h_{1} *\right), R Y\left(h_{2} *\right), R V\left(h_{3} *\right), R Z\left(h_{4} *\right)$

\begin{tabular}{lll}
\hline & $h *$ & Minimum value \\
\hline$R X\left(h_{1}\right)$ & -0.573541 & $2.354613 \times 10^{-6}$ \\
$R Y\left(h_{2}\right)$ & -0.245765 & $4.345767 \times 10^{-8}$ \\
$R V\left(h_{3}\right)$ & -0.765459 & $5.653789 \times 10^{-10}$ \\
$R Z\left(h_{4}\right)$ & -0.347556 & $7.378594 \times 10^{-12}$ \\
\hline
\end{tabular}

Table 4 The residual errors for $E R_{1}, E R_{2}, E R_{3}$ and $E R_{4}$ for $t \in(0,1)$

\begin{tabular}{lllll}
\hline$t$ & $E R_{1}\left(X, Y, V, Z ; h_{1} *\right)$ & $E R_{2}\left(X, Y, Z ; h_{2} *\right)$ & $E R_{3}\left(X, Y, V, Z ; h_{3} *\right)$ & $E R_{4}\left(X, Y, V, Z ; h_{4} *\right)$ \\
\hline 0.0 & $1.565422 \times 10^{-6}$ & $4.644621 \times 10^{-5}$ & $7.354251 \times 10^{-8}$ & $5.1546455 \times 10^{-8}$ \\
0.1 & $8.354617 \times 10^{-3}$ & $8.362652 \times 10^{-6}$ & $1.658541 \times 10^{-9}$ & $6.2414232 \times 10^{-5}$ \\
0.2 & $2.974233 \times 10^{-2}$ & $3.652652 \times 10^{-4}$ & $3.354265 \times 10^{-6}$ & $2.3454565 \times 10^{-7}$ \\
0.3 & $7.365425 \times 10^{-5}$ & $1.362669 \times 10^{-3}$ & $3.575213 \times 10^{-7}$ & $4.5448869 \times 10^{-3}$ \\
0.4 & $8.785251 \times 10^{-9}$ & $4.895132 \times 10^{-4}$ & $1.655412 \times 10^{-6}$ & $9.6548865 \times 10^{-7}$ \\
0.5 & $2.957532 \times 10^{-8}$ & $8.654261 \times 10^{-6}$ & $9.357445 \times 10^{-5}$ & $7.2154551 \times 10^{-4}$ \\
0.6 & $6.364586 \times 10^{-7}$ & $9.315562 \times 10^{-5}$ & $7.875622 \times 10^{-7}$ & $1.1455663 \times 10^{-9}$ \\
0.7 & $2.728225 \times 10^{-1}$ & $6.795355 \times 10^{-4}$ & $8.365454 \times 10^{-6}$ & $8.4688622 \times 10^{-3}$ \\
0.8 & $5.712805 \times 10^{-6}$ & $2.354544 \times 10^{-6}$ & $5.364554 \times 10^{-4}$ & $3.6455692 \times 10^{-1}$ \\
0.9 & $7.287916 \times 10^{-4}$ & $3.478846 \times 10^{-7}$ & $2.448725 \times 10^{-9}$ & $7.3514496 \times 10^{-2}$ \\
1 & $3.148699 \times 10^{-5}$ & $7.354898 \times 10^{-6}$ & $4.784662 \times 10^{-5}$ & $5.6545855 \times 10^{-6}$ \\
\hline
\end{tabular}

$$
\begin{aligned}
& R Y\left(h_{2}\right)=\int_{0}^{1}\left(E R_{2}\left(X, Y, V, Z ; h_{2}\right)\right)^{2} d t, \\
& R V\left(h_{3}\right)=\int_{0}^{1}\left(E R_{3}\left(X, Y, V, Z ; h_{3}\right)\right)^{2} d t, \\
& R Z\left(h_{4}\right)=\int_{0}^{1}\left(E R_{4}\left(X, Y, V, Z ; h_{4}\right)\right)^{2} d t .
\end{aligned}
$$

The minimal values of $R X\left(h_{1}\right), R Y\left(h_{2}\right), R V\left(h_{3}\right)$ and $R Z\left(h_{4}\right)$ are

$$
\frac{d R X\left(h_{1} *\right)}{d h_{1}}=0, \quad \frac{d R Y\left(h_{2} *\right)}{d h_{2}}=0, \quad \frac{d R V\left(h_{3} *\right)}{d h_{3}}=0, \quad \frac{d R Z\left(h_{4} *\right)}{d h_{4}}=0 .
$$

We consider the optimal values of $h_{1} *, h_{2} *, h_{3} *$ and $h_{4} *$ for all of the cases to be

$$
h_{1} *=-0.573541, \quad h_{2} *=-0.245765, \quad h_{3} *=-0.765459, \quad h_{4} *=-0.347556
$$


It is of prime importance for any patient infected with the hepatitis B virus, to be given an antiviral therapy which is being considered as one of the very efficient methods of treatment [39]. The hepatics B virus, which leads to acute liver disease, affects most of the patients during birth or after the birth. The W.H.O. report says that the $90 \%$ of the HBV infected persons get cured naturally by the biological process in one year [40]. However, in the rest of the $10 \%$ sometimes fail to show any kind of symptom of the disease.

When the patients are severely infected, it concerns around $90 \%$ of their liver cells, and hepatocytes get damaged [41, 42]. It is due to the immune response to the infected hepatocytes. There has been no specific treatment for patients with acute infection [43]. In most of the situations, it does not show any symptoms but in rare situations it shows indications like extreme fatigue nausea, vomiting and abdominal pain [38, 44-48]. It is assumed that the acute infection can be easily overcome but the problem is still there as there is evidence of many deaths. While there are enormous treatment options for the chronic patients, none of the treatment methods is found to be useful and efficient [49-51]. Clinical data shows that most of the virus gets decayed when the HBV patients undergo the therapy. Applying the mathematical models to such data shows the result that, if the patients have an immune response, they get cured very quickly when the treatment is given, and in other cases the treatment works comparatively slow [52].

Vaccine has been used for HBV infected patients from 1982. However, eradication of this disease is not possible. Today, the vaccination focused on the highest risk of developing chronic infection in children who are below 6 years old [53]. The best vaccination strategy for newborns is that the first dose has to be given within the first $24 \mathrm{~h}$ of birth [54]. Therefore, the children will be protected at the maximum rate from infection at least for 20 years. It is recommended to vaccinate for reducing the HBV infected patients. It needs to be extended to groups in high danger, such as patients requiring transplantation or dialysis, health-care workers, travelers before visiting an endemic area, people in prisons, or people with multiple sexual partners. When the vaccine is given to patients, it gives positive results for the eradication of the disease [37]. Therefore, we need a good therapy to cure patients who got infected earlier.

Mathematical models have been one of the very useful methods for the understanding of virus and drug dynamics under drug therapy in infections such as HIV, hepatitis $\mathrm{C}(\mathrm{HCV})$, and HBV. To have a deeper understanding of virus-host dynamics, spectacular studies have been done combining with the clinical data and mathematical models. However, Ciupe et al. [55] in their studies showed that a strong immune response can be the key to overcoming the disease. Similar studies have been continued to find the efficacy of drugs in curing hepatitis B. For instance, Anna et al. [56] have estimated 95\% lamivudine efficacy in blocking new virus production which can be elevated to $99 \%$ when combined with famcilovir. Thus, we have studied the comparisons of existing work $[4,5,7]$. The result is given in Table 5. In our result, the number of recovery days is smaller than the previous result.

\section{Conclusion}

The hepatitis B virus has been identified as a virulent disease that has claimed numerous lives. The antiviral therapy is acknowledged as the most appropriate method to cure this disease. In this paper, we found the mathematical solution for HBV keeping the LHAM method as a base. From the analysis, it is well understood that the antiviral therapy is very 
Table 5 Comparison study of existing work and proposed work

\begin{tabular}{lllllllllll}
\hline & $\alpha$ & $\varphi$ & $d_{\mathrm{T}}$ & $r$ & $\rho$ & $\delta$ & $c$ & $\begin{array}{l}\text { Existing } \\
\text { model }\end{array}$ & $\begin{array}{l}\text { Proposed } \\
\text { model }\end{array}$ & Reference \\
\hline$X(t)$ & 1 & $1 \times 10^{-10}$ & $1 \times 10^{-2}$ & 1.4 & 0 & 0.07 & 0.67 & & 0.0135 & {$[4,5,7]$} \\
& 1 & $2.5 \times 10^{-7}$ & $2.7 \times 10^{-3}$ & 3.5 & 0 & 0.22 & 0.7 & 0.0124 & & \\
& 1 & $1.9 \times 10^{-6}$ & $5.3 \times 10^{-3}$ & 5.6 & 0 & 0.25 & 0.18 & & & \\
& 1 & $6.6 \times 10^{-8}$ & $9 \times 10^{-4}$ & 6.4 & 0 & 0.06 & 1 & & & \\
$Y(t)$ & 1 & $1 \times 10^{-10}$ & $1 \times 10^{-2}$ & 1.4 & 0 & 0.07 & 0.67 & 0.0026 & 0.0019 & {$[4,5,7]$} \\
& 1 & $2.5 \times 10^{-7}$ & $2.7 \times 10^{-3}$ & 3.5 & 0 & 0.22 & 0.7 & & & \\
& 1 & $1.9 \times 10^{-6}$ & $5.3 \times 10^{-3}$ & 5.6 & 0 & 0.25 & 0.18 & & & \\
& 1 & $6.6 \times 10^{-8}$ & $9 \times 10^{-4}$ & 6.4 & 0 & 0.06 & 1 & & & \\
$V(t)$ & 1 & $1 \times 10^{-10}$ & $1 \times 10^{-2}$ & 1.4 & 0 & 0.07 & 0.67 & 0.0248 & 0.0278 & {$[4,5,7]$} \\
& 1 & $2.5 \times 10^{-7}$ & $2.7 \times 10^{-3}$ & 3.5 & 0 & 0.22 & 0.7 & & & \\
& 1 & $1.9 \times 10^{-6}$ & $5.3 \times 10^{-3}$ & 5.6 & 0 & 0.25 & 0.18 & & & \\
& 1 & $6.6 \times 10^{-8}$ & $9 \times 10^{-4}$ & 6.4 & 0 & 0.06 & 1 & & & \\
$Z(t)$ & 1 & $1 \times 10^{-10}$ & $1 \times 10^{-2}$ & 1.4 & 0 & 0.07 & 0.67 & 0.2258 & 0.02345 & {$[4,5,7]$} \\
& 1 & $2.5 \times 10^{-7}$ & $2.7 \times 10^{-3}$ & 3.5 & 0 & 0.22 & 0.7 & & & \\
& 1 & $1.9 \times 10^{-6}$ & $5.3 \times 10^{-3}$ & 5.6 & 0 & 0.25 & 0.18 & & & \\
& 1 & $6.6 \times 10^{-8}$ & $9 \times 10^{-4}$ & 6.4 & 0 & 0.06 & 1 & & & \\
\hline
\end{tabular}

much required for the infected patients since the virus eradication fully depends on the power of the drugs. There is no possibility to root out the virus without antiviral therapy, as has been analyzed and shown through mathematical modeling in this paper. We also have calculated and studied the comparison of the existing work with our proposed study. Thus, we strongly stress that our work takes minimum number of days to cure HBV. This research paper may be used as a platform to do a further research and to design an effective antiviral therapy and drug by opening the new future avenues in the research of nonlinear modeling in different directions. Moreover, the work of Baleanu et al. [57, 58] will be a great resource to extend this for further research. If two of their works are understood, we could extend our work effectively with some other parameter estimation.

\section{Acknowledgements}

We are thankful to Dr. J. Michael Raj and Dr. Narayana Jena, Asst. Professors of English, SRM Institute of Science and Technology for their linguistic support.

\section{Funding}

The financial assistance is not applicable.

Availability of data and materials

Data sharing is not applicable to this study.

Competing interests

We the authors state that we have no conflicts of interest.

Authors' contributions

Equally contributions have been made by all authors and the final manuscript has been read and approved.

\section{Author details}

${ }^{1}$ Research Scholar, University College of Engineering, Rajamadam, Thanjavur District, Pattukkottai 614 701, Tamil Nadu, India. ${ }^{2}$ Department of Mathematics, University College of Engineering, Rajamadam, Thanjavur District, Pattukkottai 614 701, Tamil Nadu, India. ${ }^{3}$ Department of Mathematics, Faculty of Engineering and Technology, SRM Institute of Science and Technology, Chengalpattu District, Kattankulathur 603 203, Tamil Nadu, India.

\section{Publisher's Note}

Springer Nature remains neutral with regard to jurisdictional claims in published maps and institutional affiliations. 


\section{References}

1. Su, B., Shou, W., Dorman, K.S., Jones, D.E.: Mathematical modelling of immune response in tissues. Comput. Math Methods Med. 10(1), 9-38 (2009)

2. Eikenberry, S., Hews, S., Nagy, J.D., Kuang, Y.: The dynamics of a delay model of hepatitis B virus infection with logistic hepatocyte growth. Math. Biosci. Eng. 6(2), 283-299 (2009)

3. Long, C., Qi, H., Huang, S.H.: Mathematical modeling of cytotoxic lymphocyte-mediated immune responses to hepatitis B virus infection. J. Biomed. Biotechnol. 2008, 743690 (2008)

4. Min, L., Su, Y., Kuang, Y.: Mathematical analysis of a basic virus infection model with application to HBV infection. Rocky Mt. J. Math. 38, 1573-1585 (2008)

5. Zou, L., Zhang, W., Ruan, S.: Modeling the transmission dynamics and control of hepatitis B virus in China. J. Theor Biol. 262, 330-338 (2010)

6. Thornley, S., Bullen, C., Roberts, M.: Hepatitis B in a high prevalence New Zealand population: a mathematical model applied to infection control policy. J. Theor. Biol. 254(3), 599-603 (2008)

7. Zhang, T., Wang, K., Zhang, X.: Modeling and analyzing the transmission dynamics of HBV epidemic in Xinjiang, China. PLoS ONE 10(9), e0138765 (2015)

8. Zou, L., Zhang, W., Ruan, S.: Modeling the transmission dynamics and control of hepatitis B virus in China. J. Theor Biol. 262(2), 330-338 (2010)

9. Zhang, S., Zhou, Y.: The analysis and application of an HBV model. Appl. Math. Model. 36(3), 1302-1312 (2012)

10. Mann, J., Roberts, M.: Modelling the epidemiology of hepatitis B in New Zealand. J. Theor. Biol. 269, 266-272 (2011)

11. Khabouze, M., Hattaf, K., Yousfi, N.: Stability analysis of an improved HBV model with CTL immune response. Int. Sch. Res. Not. 2014, 407272 (2014)

12. Zhang, S., Xu, X.: A mathematical model for hepatitis B with infection-age structure. Discrete Contin. Dyn. Syst., Ser. B 21(4), 1329-1346 (2016)

13. Liang, P., Zu, J., Yin, J., et al.: The independent impact of newborn hepatitis B vaccination on reducing HBV prevalence in China, 1992-2006: a mathematical model analysis. J. Theor. Biol. 386, 115-121 (2015)

14. Hajipour, M., Jajarmi, A., Baleanu, D., Sun, H.G.: On an accurate discretization of a variable-order fractional reaction-diffusion equation. Commun. Nonlinear Sci. Numer. Simul. 69, 119-133 (2019)

15. Hajipour, M., Jajarmi, A., Baleanu, D.: On the accurate discretization of a highly nonlinear boundary value problem. Numer. Algorithms 79(3), 679-695 (2018)

16. Hajipour, M., Jajarmi, A., Malek, A., Baleanu, D.: Positivity-preserving sixth-order implicit finite difference weighted essentially non-oscillatory scheme for the nonlinear heat equation. Appl. Math. Comput. 325, 146-158 (2018)

17. Dumitru, B., Mohammadi, H., Rezapour, S.: Analysis of the model of HIV-1 infection of CD4+ T-cell with a new approach of fractional derivative. Adv. Differ. Equ. 2020, 71 (2020)

18. Dumitru, B., Jajarmi, A., Mohammadi, H., Rezapour, S.: A new study on the mathematical modelling of human liver with Caputo-Fabrizio fractional derivative. Chaos Solitons Fractals 134, 109705 (2020)

19. Dumitru, B., Mousalou, A., Rezapour, S.: On the existence of solutions for some infinite coefficient-symmetric Caputo-Fabrizio fractional integro-differential equations. Bound. Value Probl. 2017, 145 (2017)

20. Dumitru, B., Mousalou, A., Rezapour, S.: The extended fractional Caputo-Fabrizio derivative of order $0 \leq \sigma<1$ on $C_{R}[0,1]$ and the existence of solutions for two higher-order series-type differential equations. Adv. Differ. Equ. 2018, 255 (2018)

21. Melike, S.A., Baleanu, D., Mousalou, A., Rezapou, S.: On high order fractional integro-differential equations including the Caputo-Fabrizio derivative. Bound. Value Probl. 2018, 90 (2018)

22. Khabouze, M., Hattaf, K., Yousfi, N.: Stability analysis of an improved HBV model with CTL immune response. Int. Sch. Res. Not. 2014, 407272 (2014)

23. Mohammadi, F., Moradi, L., Baleanu, D., Jajarmi, A.: A hybrid functions numerical scheme for fractional optimal control problems: application to non-analytic dynamical systems. J. Vib. Control 24(21), 5030-5043 (2018)

24. Wiah, E.N., Dontwi, I.K., Adetunde, I.A.: Using mathematical model to depict the immune response to hepatitis $B$ virus infection. J. Math. Res. 3(2), 157-167 (2011)

25. Ciupe, S.M., Ribeiro, R.M., Nelson, P.W., Perelson, A.S.: Modeling the mechanisms of acute hepatitis B virus infection. J. Theor. Biol. 247(1), 23-35 (2007)

26. Min, L., Su, Y., Kuang, Y.: Analysis of a basic model of virus infection with application to hbv infection. Rocky Mt. J. Math. 38(5), 1573-1585 (2008)

27. Yousfi, N., Hattaf, K., Tridane, A.: Modeling the adaptive immune response in HBV infection. J. Math. Biol. 63(5), 933-957 (2011)

28. Fatehi Chenar, F., Kyrychko, Y.N., Blyuss, K.B.: Mathematical model of immune response to hepatitis B. J. Theor. Biol. 447, 98-110 (2018)

29. Friedman, A., Siewe, N.: Chronic hepatitis B virus and liver fibrosis: a mathematical model. J. Infect. Dis. 217(9), 1408-1416 (2018)

30. Geethamalini, S., Balamuraltharan, S.: Semianalytical solutions by homotopy analysis method for EIAV infection with stability analysis. Adv. Differ. Equ. 2018, 356 (2018)

31. Liao, S.J.: Notes on the homotopy analysis method: some definitions and theorems. Commun. Nonlinear Sci. Numer Simul. 14, 983-997 (2009)

32. Liao, S.J.: Beyond Perturbation: Introduction to the Homotopy Analysis Method. Chapman \& Hall/CRC Press, Boca Raton (2003)

33. Liao, S.J.: An optimal homotopy-analysis approach for strongly nonlinear differential equation. Commun. Nonlinear Sci. Numer. Simul. 15(8), 2003-2016 (2010)

34. Liao, S.J.: Homotopy Analysis Method in Nonlinear Differential Equations. Springer, Heidelberg (2012)

35. Zhao, S., Xu, Z., Lu, Y.: A mathematical model of hepatitis B virus transmission and its application for vaccination strategy in China. Int. J. Epidemiol. 29(4), 744-752 (2000)

36. Vahidian Kamyad, A., Akbari, R., Akbar Heydari, A., Heydari, A.: Mathematical modeling of transmission dynamics and optimal control of vaccination and treatment for hepatitis B virus. Comput. Math. Methods Med. 2014, 475451 (2014)

37. Vierling, J.: The immunology of hepatitis B. Clin. Liver Dis. 727(759), 727-759 (2007) 
38. Forde, J.E., Ciupe, S.M., Cintron-Arias, A., Lenhart, S.: Optimal control of drug therapy in a hepatitis B model. Appl. Sci. 6(8), article 219 (2016)

39. Lampertico, P., Aghemo, A., Vigano, M., Colombo, M.: HBV and HCV therapy. Viruses 1, 484-509 (2009)

40. Lok, A.S.: Personalized treatment of hepatitis B. Clin. Mol. Hepatol. 21(1), 1-6 (2015)

41. Trepo, C., Chan, H.L.Y., Lok, A.: Hepatitis B virus infection. Lancet 384(9959), 2053-2063 (2014)

42. Suk-Fong Lok, A.: Hepatitis B: 50 years after the discovery of Australia antigen. J. Viral Hepatitis 23(1), 5-14 (2016)

43. Franco, E., Bagnato, B., Marino, M.G., Meleleo, C., Serino, L., Zaratti, L.: Hepatitis B: epidemiology and prevention in developing countries. World J. Hepatol. 4(3), 74-80 (2012)

44. Block, T.M., Rawat, S., Brosgart, C.L.: Chronic hepatitis B: a wave of new therapies on the horizon. Antivir. Res. 121, 69-81 (2015)

45. Bedossa, P., Patel, K., Castera, L.: Histologic and noninvasive estimates of liver fibrosis. Clin. Liver Dis. 6(1), 5-8 (2015)

46. Medley, G.F., Lindop, N.A., Edmunds, W.J., Nokes, D.J.: Hepatitis-B virus endemicity: heterogeneity, catastrophic dynamics and control. Nat. Med. 7(5), 619-624 (2001)

47. Khan, T., Zaman, G., Ikhlaq Chohan, M.: The transmission dynamic and optimal control of acute and chronic hepatitis B. J. Biol. Dyn. 11(1), 172-189 (2017)

48. Goyal, A., Murray, J.M.: Roadmap to control HBV and HDV epidemics in China. J. Theor. Biol. 423, 41-52 (2017)

49. Pang, J., Cui, J.A., Zhou, X.: Dynamical behavior of a hepatitis B virus transmission model with vaccination. J. Theor. Biol. 265(4), 572-578 (2010)

50. Van den Driessche, P., Watmough, J.: Reproduction numbers and sub-threshold endemic equilibria for compartmental models of disease transmission. Math. Biosci. 180, 29-48 (2002)

51. Zhang, S., Xu, X.: Dynamic analysis and optimal control for a model of hepatitis $C$ with treatment. Commun. Nonlinear Sci. Numer. Simul. 46, 14-25 (2017)

52. Zhao, X.Q.: Dynamical Systems in Population Biology. Springer, New York (2003)

53. Eikenberry, S., Hews, S., Nagy, J.D., Kuang, Y.: The dynamics of a delay model of HBV infection with logistic hepatocyte growth. Math. Biosci. Eng. 6, 283-299 (2009)

54. Min, L., Su, Y., Kuang, Y.: Analysis of a basic model of virus infection with application to HBV infection. Rocky Mt. J. Math. 38(5), 1573-1585 (2008)

55. Ciupe, S., Ribeiro, R., Perelson, A.: Antibody responses during hepatitis B viral infection. PLoS Comput. Biol. 10(7), 1-16 (2014)

56. Kosinska, A.D., Moeed, A., Kallin, N., Festag, J., Su, J., Steiger, K., Michel, M.-L., Protzer, U., Knolle, P.A.: Synergy of therapeutic heterologous prime-boost hepatitis B vaccination with $\mathrm{CpG}$-application to improve immune control of persistent HBV infection. Sci. Rep. 9(1), 10808 (2019)

57. Baleanu, D., Asad, J.H., Jajarmi, A.: New aspects of the motion of a particle in a circular cavity. Proc. Rom. Acad., Ser. A 19(2), 361-367 (2018)

58. Baleanu, D., Asad, J.H., Jajarmi, A.: The fractional model of spring pendulum: new features within different kernels, Proc. Rom. Acad., Ser. A 19(3), 447-454 (2018)

\section{Submit your manuscript to a SpringerOpen ${ }^{\circ}$ journal and benefit from:}

- Convenient online submission

- Rigorous peer review

- Open access: articles freely available online

- High visibility within the field

- Retaining the copyright to your article

Submit your next manuscript at $\boldsymbol{\nabla}$ springeropen.com 